\title{
Standartlaştırılmış Yağış İndeksi (SYİ) Yöntemi ile Kızılırmak Deltası (Samsun) Kuraklık Analizi
}

\author{
${ }^{* 1}$ Erhan Şener \\ ${ }^{* 1}$ Süleyman Demirel Üniversitesi, Uzaktan Algllama Araștırma ve Uygulama Merkezi, Isparta, Türkiye
}

\begin{abstract}
Özet
Son yıllarda, mevcut su kaynakları üzerinde küresel iklim değişikliğinin olumsuz etkileri açıkça gözlenmektedir. Kızılırmak Deltası içerinde birçok su kütlesi barındıran ülkemizin en büyük ve en önemli sulak alanlarından birisidir. Özellikle delta içerisindeki yüzey sularında önemli miktarlarda hacim kayıpları yaşanmaktadır. Bu çalışmada, standartlaştırılmış yağış indeksi (SYİ) yöntemi kullanılarak Kızılırmak Deltasına yönelik kuraklık analizi yapılmıştır. Bunun için delta içerisinde ve çevresinde bulunan Samsun ve Bafra meteoroloji istasyonlarına ait yağış verileri kullanılmıştır. Kızılırmak Deltası'nın kuraklık analizine göre her bir istasyon için belirlenen yağışlı ve kurak dönemler genel olarak biribirleri ile uyum göstermektedir. Özellikle 2013-2015 yılları arasında kurak dönemler izlenirken 2010, 2012, 2016 yılları genel olarak yağışlı dönemler yaşandığı belirlenmiş̧tir.
\end{abstract}

Key words: Meteorolojik Kuraklık, Standartlaştırılmış Yağış İndeksi (SYI), Kızılırmak Deltası

\section{Giriş}

Kuraklık, dünya çapında ekonominin çeşitli sektörlerini ve çevresel faktörleri etkileyen büyük bir doğal tehlike olarak kabul edilmektedir. Kuraklık etkisi ortama düşen yağıştan başlayarak yüzey suyu sistemlerinde akarsu akışıyla, yeraltısuyu akiferlerinde beslenme ve depolanmayla biten hidrolojik döngünün hemen hemen tüm aşamalarını etkilemektedir [1]. Geleneksel olarak, kuraklıklar incelenen parametreler ile karakterize edilir ve başlıca meteorolojik (yağış, potansiyel buharlaşma-terleme), hidrolojik (akarsu akışı veya yeraltı suyu yeniden yüklenmesi) ve tarımsal (toprak nemi) kuraklık olarak sinıflandırılmaktadır [2]. Meteorolojik kuraklık, yağışların azalmasına bağlı olarak ortama düşen yağışların uzun yıllar yağış ortalamasından sapmalar göstermesi ile ortaya çıkmaktadır. Bu kuraklık hidrolojik ve tarımsal kuraklıktan önce başlamaktadır. Meteorolojik kurağın belirlenmesi ve doğru yönetimi için yapılan izleme ve değerlendirmeler farklı indeks yöntemleri geliştirilmiştir. Sözkonusu kuraklık indekslerinden en önemlileri Standartlaştırılmış Yağış İndeksi [3]., Palmer Kuraklık İndeksi [4], Standart Yağış Buharlaşma İndeksi [5], NormalinYüzdesi İndeksi [6], Keşif Kuraklık İndeksi [7], Ondalıklar İndeksi [8], Standartlaştırılmış Akım İndeksi [9], Standartlaştırılmış Yeraltısuyu İndeksi, Standartlaştırılmış Rezervuar İndeksi , China Z indeksi, Efektif Kuraklık İndeksi, Normalleştirilmiş Bitki Fark İndeksi (NDVI), Bitki Durum İndeksi (VCI)'dir. Söz konusu

\footnotetext{
* Sorumlu Yazar: Adres: Süleyman Demirel Üniversitesi, Uzaktan Algılama Araştırma ve Uygulama Merkezi, Isparta, Türkiye. E-mail address: erhansener@sdu.edu.tr, Phone: +902462111585
} 
indekslerde yağış başta olmak üzere sıcaklık, potansiyel buharlaşma ve terleme en sık olarak kullanılan girdi parametrelerindendir. Bu çalışmada Kızılırmak Deltasında Standartlaştırılmış Yağış İndeksi kullanılarak 1 yıllık zaman ölçeğinde kuraklık analizi gerçekleştirilmiştir.

\section{Materyal ve Metod}

\section{1. Çalışma alanı}

Kızılırmak Deltası, Türkiye'nin ikinci büyük nehir havzasında yer almaktadır ve yüzölçümü 56000 ha'dır (Şekil 1). Kızılırmak Nehri tarafından taşınan alüvyonlardan oluşmakta olan delta içerisinde Bafra, 19 Mayıs ve Alaçam ilçeleri önemli yerleşim yerleridir. Deltanın geniş alanları (yaklaşık 24.000 ha) sulak alan olup deniz, nehir, göl, sazlık, bataklık, çayır, sel ormanları, mera, kumul ve tarım alanları gibi farklı habitat türlerine sahiptir. Çalışma alanında birçok göl bulunmaktadır. Bunlardan en önemlileri Balık Gölü (1389 ha), Cernek Gölü (589 ha), Liman Gölü (272 ha), G1c1 Gölü (125 ha), Tatlı Gölü (52 ha), Uzun Göl (293 ha) ve Karaboğaz Gölü'dür. (170 ha). Ayrıca Altınlı Gölü, Sülüklü Gölü ve Mülk Gölü de bulunmaktadır. Çalışma alanı genellikle 1lıman bir iklime sahiptir. Bununla birlikte Akdağ ve Canik Dağları'nın etkisi, yağışların bol olduğu Karadeniz Bölgesi'nin iç kesimlerinde ve dağ ikliminde görülür [10].

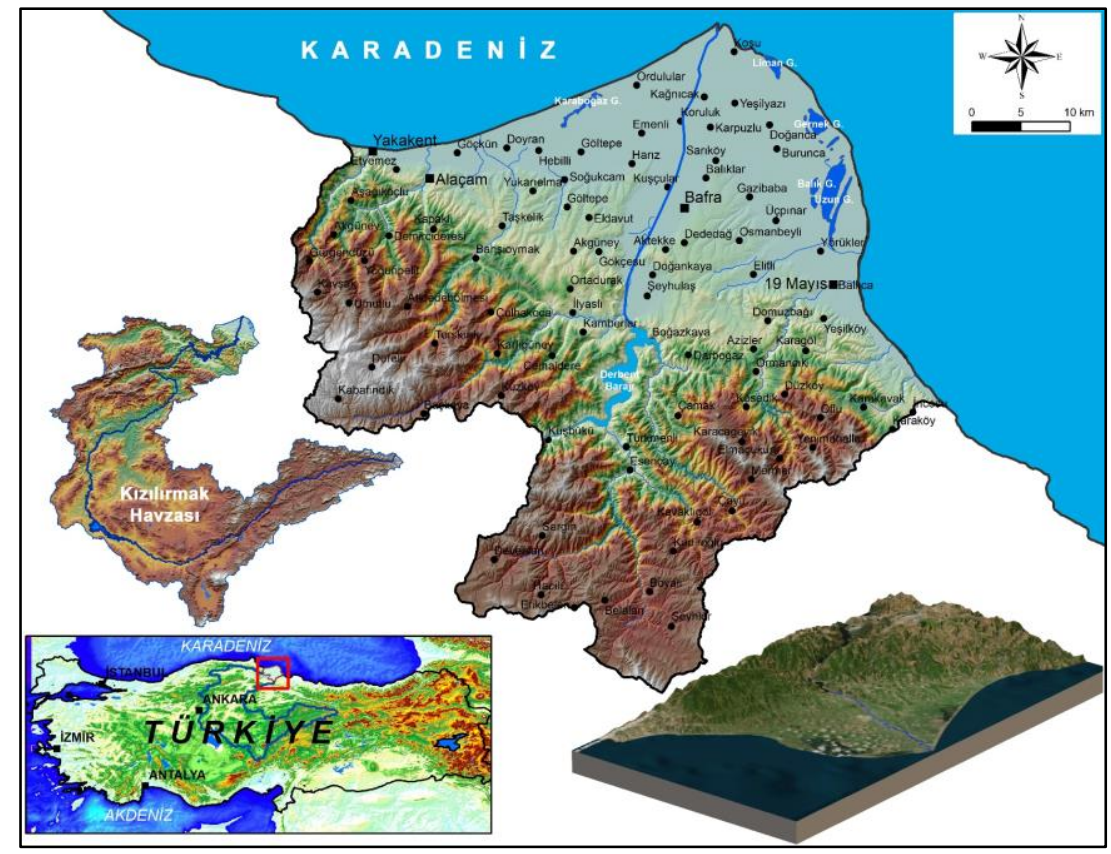

Şekil 1. Çalışma alanının yer bulduru haritası [10].

\subsection{Metod}

Çalışmada Kızılırmak Deltasındaki meteorolojik kuraklığın belirlenebilmesinde çalışma alanının yakın çevresinde bulunan Bafra ve Samsun Devlet Meteoroloji İstasyonlarının (DMİ) uzun yıllara ait meteorolojik gözlem verileri kullanılmıştır. Standartlaştırılmış Yağış İndeksi (SYİ) kullandığ́ 
veriler nispeten kolay bulunabilir olmasından dolayı literatürde en yaygın olarak kullanılan kuraklık indekslerinden birisidir [3].

Standartlaştırılmış Yağış İndeksi ile yapılan meteorolojik kuraklık analizlerinde kuraklık sınıfları, standart normal (Gaussian) dağılımlı yağış verileri kullanılarak elde edilir. Genellikle yağış verilerine en iyi uyan olasılık dağılımı Gamma olasılık dağılımı olduğundan Standartlaştırılmış Yağış İndeksi ile yapılan analizlerde, yağış verilerinden elde edilen olasılık dağılım fonksiyonları Gamma olasılık dağılım fonksiyonlarına dönüştürülmektedir [3, 11, 12].

$g(x)=\frac{1}{\beta^{\alpha} \Gamma(\alpha)} x^{\alpha-1} e^{x / \beta} \quad \mathrm{x}>0$ için

Burada; $\quad \Gamma(\alpha)$ : Gamma Dağılımı, $\quad \alpha$ : şekil parametresi $(\alpha>0), \quad \beta$ : ölçek parametresi $(\beta>0)$, $x$ : yağış miktarını $(x>0)$ ifade eder.

$\alpha$ ve $\beta$ ‘nın tahmininde maksimum olasılık çözümlerin kullanılır. Buna göre;

$\alpha=\frac{1}{4 A}\left(1+\sqrt{1+\frac{4 A}{3}}\right)$

$\beta=\frac{\bar{x}}{\alpha}$

$A=\ln (\bar{x})-\frac{\sum \ln (x)}{n}$

Burada n yağış gözlem sayısını ifade etmektedir. Mevcut verilerden elde edilen bu olasılık tanımlamaları daha sonra herhangi bir ayda gözlenmiş bir değerin kümülatif olasılığını bulmak için kullanılabilir. Bu durumda kümülatif olasılık aşağıdaki şekilde tanımlanır [13].

$G(x)=\int_{0}^{x} g(x) d x=\frac{1}{\beta^{\alpha} \Gamma(\alpha)_{0}} \int_{0}^{x} x^{\alpha-1} e^{-x / \beta_{d x}}$

Gamma fonksiyonu $\mathrm{x}=0$ için tanımsız olduğundan ve yağış dağılımı sıfır (0) değerler içerdiğinden kümülatif olasılık yeniden aşağıdaki şekilde tanımlanır[13].

$H(x)=q+(1-q) G x$

Bir sonraki aşamada, gamma dağılım fonksiyonundan elde edilen yağış olasılıkları, ters-standart normal dağılım fonksiyonu kullanılarak standart yağışlara dönüştürülür. Bu yolla ortalaması sıfır 
ve varyansı (değişkesi) bir olan standartlaştırılmış yağışlar elde edilir. Standart Yağış İndisi (SYI), belirlenen zaman dilimi içinde yağışın ortalamadan olan farkının standart sapmaya bölünmesi ile elde edilir [3].

$$
S Y \dot{I}=\frac{X_{i}-\bar{X}_{i}}{\sigma}
$$

Burada;

SYİ: Standartlaştırılmış Yağış İndeksi

$X_{i}$ : Yı1lık yă̆ı̧̧ miktarının normalleştirilmiş miktarı,

$\bar{X}_{i}$ : Her bir istasyon için seçilen zaman aralığında yağış ortalaması

$\sigma$ : Her bir istasyona ilişkin değerlerin zaman aralığı içindeki standart sapmasını ifade eder.

Tablo 1. Standartlaştırılmış Yağış İndisi (SYİ) Kuraklık sınıflaması [3].

\begin{tabular}{|c|c|}
\hline Yağış (Kuraklık/Nemlilik) Sınıfı & Standart Yağış İndisi (SYİ) \\
\hline Așırı yağışıı & 2 ve üzeri \\
\hline Çok yağış̧1 & $1.5-1.99$ \\
\hline Orta yağ & $1-1.49$ \\
\hline Normale yakın nemli & $0.5-0.99$ \\
\hline Normal & $-0.499-0.499$ \\
\hline Normale yakın kurak & $-0.5--0.99$ \\
\hline Orta düzeyde kurak & $-1--1.49$ \\
\hline Şiddetli kurak & $-1.5--1.99$ \\
\hline Așırı kurak & -2 ve altı \\
\hline
\end{tabular}

\section{Bulgular ve Tartışma}

Kuraklık analizleri Bafra ve Samsun meteoroloji istasyonları için ayrı ayrı yapılarak ölçüm süreleri boyunca yıllara göre kuraklık durumları incelenmiş̧tir. Bafra meteoroloji istasyonu için hazırlanmış olan SYI grafiğine göre 2004 ve 2012 yılları aşırı yağışlı, 2014 yılında ise aşırı kurak dönemler izlenmiştir. 53 yıllık ölçüm periyodunda 25 yıl yağışlı, 28 yıl kurak dönemler yaşanmıştır. Bu kurak dönemler genel olarak hafif ve orta kurak dönemler olarak belirlenmiştir (Şekil 2). Samsun Bölge meteoroloji istasyonu için hazırlanmış olan SYI grafiğine göre 1939, 1967 ve 2012 yıllarında aşırı yağışlı, 1950, 1964 ve 1981 yıllarında ise çok kurak dönemler izlenmiştir. 87 yıllık ölçüm periyodunda 39 yıl yağışlı, 48 yıl kurak dönemler yaşanmıştır. Bu kurak dönemler genel olarak hafif ve orta kurak dönemler olarak belirlenmiştir (Şekil 3). Kızılırmak Deltası'nın kuraklık analizini yapabilmek için tüm istasyonların verileri tek bir grafik üzerinde gösterilmiş̧ir (Şekil 4). Buna göre her bir istasyon için belirlenen yağışlı ve kurak dönemler genel olarak birbirleri ile uyum göstermektedir. Özellikle 2013-2015 yılları arasında kurak dönemler izlenirken 2010, 2012, 2016 yılları genel olarak yağışlı dönemleri göstermektedir. 1999-2003 yılları kurak dönemler iken 20042005 yılları yağışlı geçmiştir. 1983, 1993-1995 yılları arası kurak dönemler, 1987-1989 ve 19911992 yılları yağışlı dönemlerdir. 


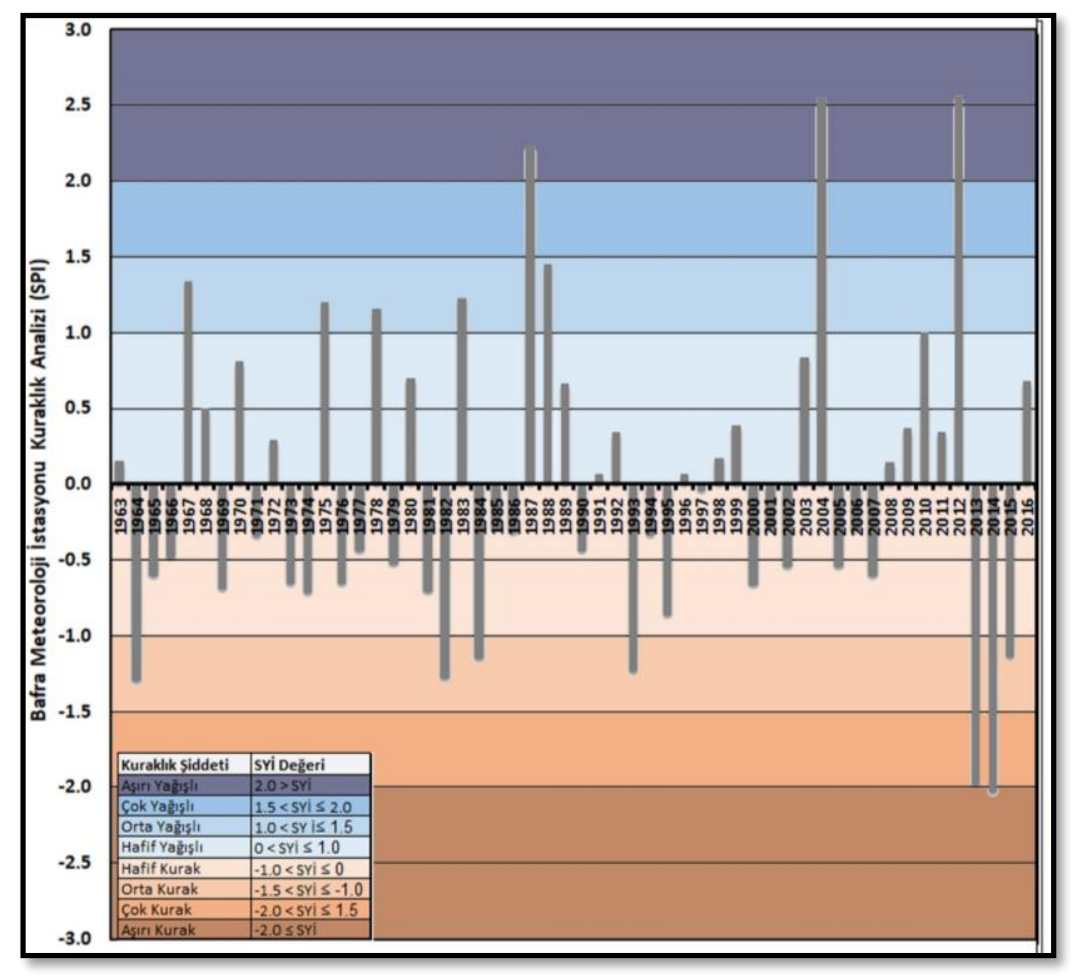

Şekil 2. Bafra meteoroloji istasyonuna ait SYİ grafiği

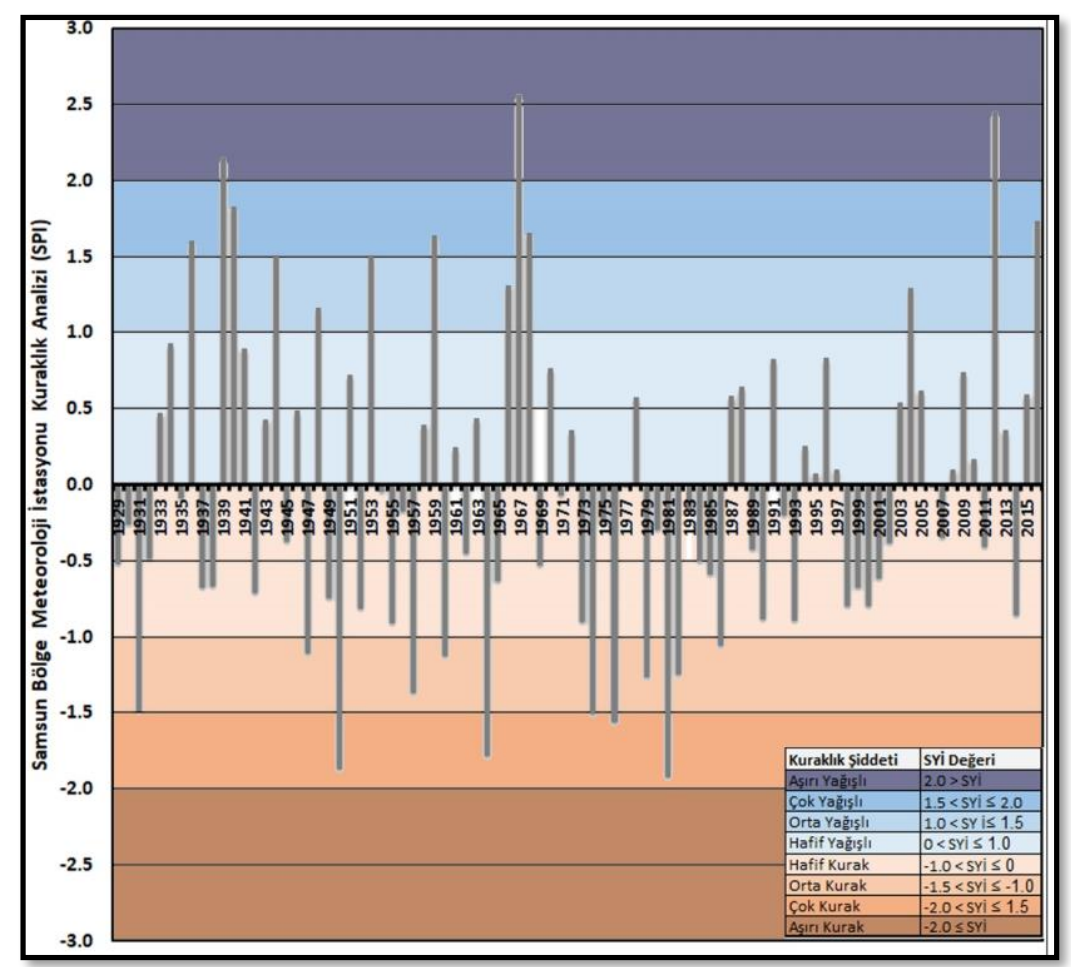

Şekil 3. Samsun Bölge meteoroloji istasyonuna ait SYİ grafiği 
Tüm istasyonların SYİ verileri birleştirilerek (ortalamaları alınmıştır) uzun yıllar SYİ değerlerine göre ortalamadan sapmaları incelendiğinde yağışlı geçen yılların $(n=49)$ kurak yıllara $(n=36)$ göre daha fazla olduğu buna karşılık 2016 yılının kurak olduğu gözlenmektedir (Şekil 4).

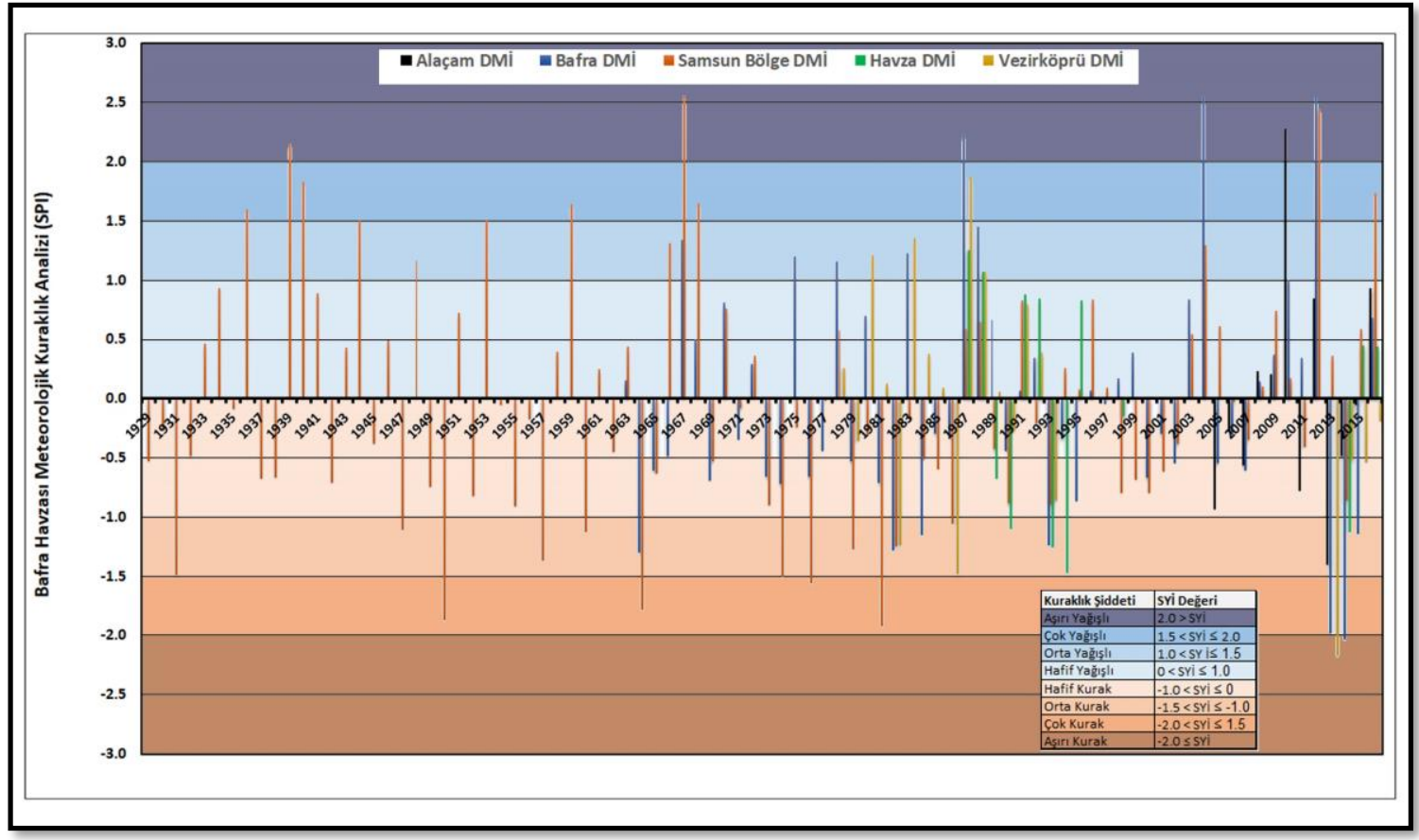

Şekil 4. Kızılırmak Deltası genel kuraklık analizi

\section{Sonuçlar}

Kuraklığın etkilerinin en aza indirilebilmesi için yapılması gereken en temel incelemelerden biri geçmişten günümüze yaşanan kuraklıkların doğru olarak tanımlanarak gelecekteki olası kuraklıkların tahmin edilmesidir. Bu çalışmada Kızılırmak Deltası için yapılan kuraklık analizleri çalışma alanının yakın çevresinde bulunan Bafra ve Samsun Devlet Meteoroloji İstasyonlarının (DMI) uzun yıllara ait meteorolojik gözlem verileri ile Standartlaştırılmış Yağış İndeksi yöntemi kullanılarak gerçekleştirilmiştir. Elde edilen sonuçlara göre geçmiş dönemde kısmen yağışl1 dönemler yaşanmış olsa da 2000 yılından itibaren kurak dönemlerin baskın bir şekilde yaşandığ belirlenmiştir.

\section{Teşekkür}

Bu çalışma, Samsun Büyükşehir Belediyesi adına "KIZILIRMAK DELTASI SU AYAK IZININ BELIRLENMESI ALT PROJESI" kapsamında yapılmış olup yazar, projeyi finansal olarak destekleyen Samsun Büyükşehir Belediyesi’ne teşekkür eder. 


\section{Kaynaklar}

[1] Tsakiris, G., Nalbantis, I., Vangelis, H., Verbeiren, B., Huysmans, M., Tychon, B., Jacquemin, I., Canters, F., Vanderhaegen, S., Engelen, G., Poelmans, L., De Becker, P., Batelaan, O., A system-based paradigm of drought analysis for operational management. Water Resources Management, 2013. 27, 5281-5297.

[2] Şener, E., Küresel İklim Değişikliğinin Eğirdir Gölü Havzasına Etkileri ve Kuraklık Analizi, SDÜ Fen Bilimler Enstitüsü, Doktora Tezi, 2021, 413 s.

[3] McKee, T.B., N.J. Doesken and J. Kleist, The Relationship of Drought Frequency and Duration

to Time Scales. Proceedings of the 8th Conference on Applied Climatology, 17-22 January 1993, Anaheim, CA. Boston, MA, American Meteorological Society.

[4] Palmer W.C., Meteorological drought: US Department of Commerce, Weather Bureau, Cilt: 45, 1965, Washington, DC.

[5] Vicente-Serrano S.M., Beguería S., López-Moreno J.I., A multiscalar drought index sensitive to global warming: The standardized precipitation evapotranspiration index. Journal of Climate, 2010, 23, 1696-1718.

[6] Willeke G., Hosking J.R.M., Wallis J.R., Guttman N.B., The National Drought Atlas, Institute for Water Resources Report 1994, 94 NDS-4, U.S.

[7] Tsakiris G., Vangelis H.J.E.W., Establishing a drought index incorporating evapotranspiration, European water, 2005, 9(10), 3-11.

[8] Gibbs W.J., Maher, J.V., Rainfall Deciles as Drought Indicators, Bureau of Meteorology Bulletin, 48, 1967, Melbourne, Australia.

[9] Shukla S., Wood A., Use of a Standardized Runoff Index For Characterizing Hydrologic, Geophysical Research Letters, 2008, 35, 1-7.

[10] Samsun Büyükşehir Belediyesi, Kızılırmak Deltası Su Ayak İzinin Belirlenmesi - Alt Proje Raporu, 2018, 594 s.

[11] McKee, T. B., Doesken, N. J., \& Kleist, J. 1995. Drough tmonitoring with multiple time scales. Ninth Conference on Applied Climatology (s. 233-236). Boston: American Meteorological Society.

[12] Thom, H. C. S. 1966. Some Methods of Climatological Analysis. WMO Technical Note No. 81, World Meteorological Organization, Geneva, Switzerland, 63 pp.

[13] Şener, E., \& Şener, Ş. (2021). SPI ve CZI Kuraklık İndislerinin CBS Tabanlı Zamansal ve Konumsal Karşılaştırması: Burdur Gölü Havzası Örneği. Doğal Afetler ve Çevre Dergisi, 7(1), 4158. 